\title{
Epidemiological Profile of Road Traffic Accidents Involving Motorized Two-wheelers in Urban Areas in Benin
}

\author{
François Agossou*, Jacques Saizonou, Virginie Mongbo, Blasselle Houssou, Edgard-Marius Ouendo
}

Regional Institute of Public Health, Ouidah, Benin

Received April 3, 2020; Revised April 29, 2020; Accepted June 4, 2020

Copyright ( $(2020$ by authors, all rights reserved. Authors agree that this article remains permanently open access under the terms of the Creative Commons Attribution License 4.0 International License

\begin{abstract}
Motorcyclists are among vulnerable road users and account for $28 \%$ of road traffic fatalities worldwide. In Benin, the problem is accentuated in large cities such as Cotonou and Parakou, where road transport is dominated by motorized two-wheelers. This paper aimed to study the epidemiological profile of RTAs involving motorized two-wheelers in Cotonou and Parakou (Benin), from 2016 to 2017. This was a retrospective study based on the database of the National Centre for Road Safety. This is a public institution in charge of implementing the road safety policy and road traffic accident surveillance at the national level. Logistic regression was applied to assess the associations between independent variables and the outcome variable. The level of statistical significance was set at $\mathrm{p}<0.05$. From 2016 to $2017,1,628$ road traffic accidents involving motorized two-wheelers were recorded in Cotonou and Parakou, of which 62 (3.81\%) were fatal. RTAs recorded in Parakou $(\mathrm{AOR}=2.52,95 \% \mathrm{CI}=1.29-4.93)$, single-vehicle crashes $(\mathrm{AOR}=7.73,95 \% \mathrm{CI}=2.70-22.07)$, collisions between motorized two-wheelers and trucks (AOR = 12.42, $95 \%$ CI $=6.16-25.04)$, collisions between motorized two-wheelers and pedestrians $(\mathrm{AOR}=6.46$, $95 \% \mathrm{CI}=2.70-15.47$ ) and time slot from midnight to 6 a.m. $(\mathrm{AOR}=3.88,95 \% \mathrm{CI}=1.61-9.34)$ were significantly more deadly. Measures targeting motorcyclists should be undertaken such as the implementation of an integrated model of communication strategies.
\end{abstract}

Keywords Road Traffic Accident, Factors, Motorized Two-wheelers, Urban Areas, Benin

\section{Introduction}

Globally, 1.35 million people die and millions more are disabled because of Road Traffic Accidents (RTAs) each year [1]. Besides, global losses due to RTAs are estimated to amount to USD 518 billion annually, with a cost to states of between 1 and 3\% of Gross Domestic Product $[2,3]$. RTAs are, therefore, a major public health and socioeconomic problem worldwide and particularly in Africa, where the risk of dying because of a road traffic injury is the highest (26.6 per 100,000 population) [1]. Motorcyclists (drivers or passengers of motorized two-wheelers) are among the most vulnerable road users [4]. According to the World Health Organization [1], motorcyclists account for $28 \%$ of road traffic fatalities worldwide. African countries where motorcycles are widely used, such as Benin have the highest rates of deaths because of RTAs [5].

In Benin, the problem is too pronounced in large cities such as Cotonou and Parakou, which are characterized by a high density of motorized two-wheelers. With the economic development of these cities, the population's demand for transport has increased. However, as the supply of public transport is poorly developed at the national and local levels, this demand could not be met. As a result, there has been a massive importation of motorcycles for personal use because of their low cost of acquisition and maintenance compared to cars. This situation has favored the emergence for several years of commercial motorcyclists, which today represent the preferred means of transport for the population.

Factors that could justify the greater exposure of motorcyclists are multiple. According to Haddon [6], an RTA is rarely because of a single cause. It results from the system made up of the driver, vehicle, and environment [6]. As motorcyclists account for most road traffic fatalities, an effective policy to reduce their 
involvement would lead to a significant reduction in the number of road traffic deaths. This requires knowledge of determinants of post-crash death among users of motorized two-wheelers. In the Beninese literature, very little research has addressed factors associated with RTAs among road users and motorcyclists in particular. The studies available on the subject are generally carried out in hospitals $[7,8]$. These studies are, therefore, subject to selection bias.

This paper aimed to study the epidemiological profile of RTAs involving motorized two-wheelers in Cotonou and Parakou from 2016 to 2017, based on data provided by the National Centre for Road Safety. Specifically, the purpose of this study was to describe RTAs involving motorized two-wheelers and to identify factors associated with their severity.

\section{Materials and Methods}

\subsection{Study Setting}

Benin is a West African country with an area of 114,763 km² [9]. Benin has 12 departments divided into 77 municipalities, including Cotonou and Parakou [9]. They counted the highest numbers of motorized two-wheelers in southern and northern Benin, respectively. Compared to other cities in Benin, Cotonou and Parakou have the most developed economic activities. They also have more extensive road and health infrastructures, such as the Departmental and University Hospital Center in Parakou and the National Hospital and University Center in Cotonou. The population of Cotonou and Parakou was estimated at 760,000 and 255,478 inhabitants, respectively, in 2013 [9].

\subsection{Study Design, Population and Study Period}

This was a retrospective record-based study. All RTAs involving motorized two-wheelers and occurring from 2016 to 2017 in Cotonou or Parakou have been included. In this study, we used the database of the National Centre for Road Safety. The National Centre for Road Safety is a public institution in charge of implementing the national road safety policy and road traffic accident surveillance. As a result, it has a database of RTAs occurring on the entire national road network. This database involves data collected by police officers when they observe an RTA.

\subsection{Variables}

The outcome variable was the severity of RTAs. It was categorized into two modalities: "fatal" if at least one road user involved in an RTA was dead and "no-fatal" if not. The independent variables were: location (Cotonou or Parakou), year (2016 or 2017), quarter (1st quarter, 2nd quarter, 3rd quarter or 4th quarter), day (Monday to Wednesday or Weekend), time (midnight to 6 a.m., 6 a.m. to noon, noon to 6 p.m. or 6 p.m. to midnight) and type of collision (single-vehicle crash; crash with a truck, car, motorized two-wheelers, pedestrian or other).

\subsection{Data Analysis}

The statistical analysis was conducted using Stata 11. Variables were described by calculating frequencies and percentages. Binary logistic regression was used to identify factors associated with the severity of RTAs. Bivariate analysis was used to check which independent variables were associated with the dependent variable with $\mathrm{p}$-value $<0.20$. Variables found to have an association were entered into a backward stepwise model for controlling the effects of confounders. The level of statistical significance was set at $\mathrm{p}<0.05$. Odds Ratios (OR) and 95\% Confidence Intervals (95\% CI) were used to assess the relationship between independent variables and the outcome variable. The Hosmer-Lemeshow test was used to assess goodness-of-fit.

\subsection{Ethical and Administrative Approval}

We had requested and got authorization from members of the management team of the National Centre for Road Safety to access the database used in this study. Besides, this study was part of a more global research project, the protocol of which was accepted after submission to the National Health Research Ethics Committee.

\section{Results}

\subsection{Characteristics of RTAs involving Motorized Two-wheelers}

Table 1 shows the characteristics of RTAs involving motorized two-wheelers in Cotonou and Parakou from 2016 to 2017. Overall, there were 1,628 RTAs (835 in 2016 vs. 793 in 2017) involving motorized two-wheelers recorded in Cotonou and Parakou. Cotonou accounted for $89.56 \%$ of this total vs. Parakou accounted for $10.44 \%$. There was an increase in the number of RTAs from the second quarter when it reached its peak $(38.82 \%$ in Parakou and $29.01 \%$ in Cotonou) before gradually decreasing in the third quarter and then in the fourth quarter when it reached its lowest level (10\% in Parakou and $20.03 \%$ in Cotonou). Most of the RTAs occurred from Monday to Wednesday (69.41\% in Parakou and $72.43 \%$ in Cotonou). Between midnight and 6 a.m., the frequency of RTAs was the lowest (4.12\% in Parakou and $5.49 \%$ in Cotonou). In Cotonou, RTAs were more frequent during noon to 6 p.m. (34.29\%), followed by 6 a.m. to noon (30.32\%) and 6 p.m. to midnight $(29.90 \%)$. In Parakou, the highest number of RTAs (35.88\%) was 
recorded from 6 p.m. to midnight, followed by noon to 6 p.m. (31.76\%). Crashes between motorized two-wheelers and cars were the most recorded collision mechanisms (62.96\% in Cotonou and $41.76 \%$ in Parakou).

\subsection{Bivariate Analysis}

Table 2 presents the findings of bivariate analysis. Of RTAs studied, 62 (3.81\%) were fatal. RTAs recorded in Parakou were more lethal than those observed in Cotonou $(p=0.001)$. There was no significant difference in the severity of RTAs between 2016 and 2017 ( $p=0.180)$. The severity of RTAs did not vary according to the quarter of the year. On weekends, RTAs were more lethal compared to those observed from Monday to Wednesday, with no statistically significant difference $(p=0.435)$. RTAs recorded from midnight to 6 a.m. were significantly more lethal than those observed from noon to 6 p.m. $(p=0.000)$. Single-vehicle crashes $(\mathrm{p}=0.000)$, crashes between motorized two-wheelers and trucks $(\mathrm{p}=0.000)$, or crashes between motorized two-wheelers and pedestrians ( $\mathrm{p}=$ 0.000 ) were more lethal than collisions between motorized two-wheelers and cars.

\subsection{Multivariate Analysis}

Table 2 shows the findings of multivariate analysis. RTAs in Parakou were 2.52 times $(95 \% \mathrm{CI}=1.29-4.93)$ more lethal than those observed in Cotonou after adjusting for covariates. RTAs occurring between midnight and 6 a.m. were 3.88 times $(95 \% \mathrm{CI}=1.61-9.34)$ more lethal than those recorded between noon and 6 p.m. after adjusting for covariates. Single-vehicle collisions, collisions between motorized two-wheelers and trucks, and collisions between motorized two-wheelers and pedestrians were $7.73(95 \% \mathrm{CI}=2.70-22.07), 12.42$ $(95 \% \mathrm{CI}=6.16-25.04)$ and 6.46 times $(95 \% \mathrm{CI}=2.70-$ 15.47) more lethal, respectively, than collisions between motorized two-wheelers and cars after adjusting for covariates.

Table 1. Characteristics of RTAs involving motorized two-wheelers in Cotonou and Parakou from 2016 to 2017

\begin{tabular}{|c|c|c|c|c|c|c|c|}
\hline \multirow{2}{*}{\multicolumn{2}{|c|}{ Variables }} & \multicolumn{2}{|c|}{ Parakou } & \multicolumn{2}{|c|}{ Cotonou } & \multicolumn{2}{|c|}{ Total } \\
\hline & & $\mathbf{n}_{1}{ }^{*}$ & $\%$ & $\mathbf{n}_{2}^{*}$ & $\%$ & $\mathbf{n}^{*}$ & $\%$ \\
\hline \multicolumn{8}{|c|}{ Year } \\
\hline \multicolumn{2}{|c|}{2016} & 74 & 43.53 & 761 & 52.19 & 835 & 51.29 \\
\hline \multicolumn{2}{|c|}{2017} & 96 & 56.47 & 697 & 47.81 & 793 & 48.71 \\
\hline \multicolumn{8}{|c|}{ Quarter } \\
\hline \multicolumn{2}{|c|}{ 1st quarter } & 47 & 27.65 & 374 & 25.65 & 421 & 25.86 \\
\hline \multicolumn{2}{|c|}{$2^{\text {nd }}$ quarter } & 66 & 38.82 & 423 & 29.01 & 489 & 30.04 \\
\hline \multicolumn{2}{|c|}{$3^{\text {rd }}$ quarter } & 40 & 23.53 & 369 & 25.31 & 409 & 25.12 \\
\hline \multicolumn{2}{|c|}{$4^{\text {th }}$ quarter } & 17 & 10.00 & 292 & 20.03 & 309 & 18.98 \\
\hline \multicolumn{8}{|c|}{ Day } \\
\hline \multicolumn{2}{|c|}{ Monday - Wednesday } & 118 & 69.41 & 1056 & 72.43 & 1174 & 72.11 \\
\hline \multicolumn{2}{|c|}{ Week-end } & 52 & 30.59 & 402 & 27.57 & 454 & 27.89 \\
\hline \multicolumn{8}{|c|}{ Time } \\
\hline Midnight & 06 a.m. & 7 & 4.12 & 80 & 5.49 & 87 & 5.34 \\
\hline 06 a.m. & Noon & 48 & 28.24 & 442 & 30.32 & 490 & 30.10 \\
\hline Noon & 06 p.m. & 54 & 31.76 & 500 & 34.29 & 554 & 34.03 \\
\hline 06 p.m. & Midnight & 61 & 35.88 & 436 & 29.90 & 497 & 30.53 \\
\hline \multicolumn{8}{|c|}{ Type of collision (collision with) } \\
\hline \multicolumn{2}{|c|}{ Only } & 5 & 2.94 & 40 & 2.74 & 45 & 2.76 \\
\hline \multicolumn{2}{|c|}{ Truck } & 27 & 15.88 & 110 & 7.54 & 137 & 8.42 \\
\hline \multicolumn{2}{|c|}{ Car } & 71 & 41.76 & 918 & 62.96 & 989 & 60.75 \\
\hline \multicolumn{2}{|c|}{ Two-Wheelers } & 55 & 32.55 & 151 & 10.36 & 206 & 12.65 \\
\hline \multicolumn{2}{|c|}{ Pedestrian } & 9 & 5.29 & 92 & 6.31 & 101 & 6.20 \\
\hline \multicolumn{2}{|c|}{ Other } & 3 & 1.76 & 147 & 10.08 & 150 & 9.21 \\
\hline
\end{tabular}

\footnotetext{
${ }^{\mathrm{a}}$ frequency
} 
Table 2. Factors associated with fatal RTAs involving motorized two-wheelers in Cotonou and Parakou from 2016 to 2017

\begin{tabular}{|c|c|c|c|c|c|c|c|c|c|c|}
\hline \multirow{2}{*}{\multicolumn{3}{|c|}{ Variables }} & \multirow{2}{*}{$\mathbf{n}^{*}$} & \multirow{2}{*}{$\begin{array}{c}\text { Fatal RTAs } \\
(\%)\end{array}$} & \multicolumn{3}{|c|}{ Bivariate analysis } & \multicolumn{3}{|c|}{ Multivariate analysis } \\
\hline & & & & & $\mathbf{U O R}^{* *}$ & $95 \% \mathrm{CI}$ & p-value & $\mathrm{AOR}^{* * *}$ & $95 \% \mathrm{CI}$ & p-value \\
\hline \multicolumn{11}{|c|}{ Location } \\
\hline \multicolumn{3}{|c|}{ Cotonou } & 1458 & 3.22 & 1.00 & & & 1.00 & & \\
\hline \multicolumn{3}{|c|}{ Parakou } & 170 & 8.82 & 2.90 & $\begin{array}{c}1.58- \\
5.31\end{array}$ & 0.001 & 2.52 & $1.29-4.93$ & 0.007 \\
\hline \multicolumn{11}{|c|}{ Year } \\
\hline \multicolumn{3}{|c|}{2016} & 835 & 4.43 & 1.42 & $\begin{array}{c}0.84- \\
2.38\end{array}$ & 0.180 & & & \\
\hline \multicolumn{3}{|c|}{2017} & 793 & 3.15 & 1.00 & & & & & \\
\hline \multicolumn{11}{|c|}{ Quarter } \\
\hline \multicolumn{3}{|c|}{ 1st quarter } & 421 & 4.04 & 1.40 & $\begin{array}{c}0.61- \\
3.18\end{array}$ & 0.420 & & & \\
\hline \multicolumn{3}{|c|}{$2^{\text {nd }}$ quarter } & 489 & 4.09 & 1.42 & $\begin{array}{c}0.63- \\
3.16\end{array}$ & 0.389 & & & \\
\hline \multicolumn{3}{|c|}{$3^{\text {rd }}$ quarter } & 409 & 3.91 & 1.35 & $\begin{array}{c}0.59- \\
3.11\end{array}$ & 0.471 & & & \\
\hline \multicolumn{3}{|c|}{$4^{\text {th }}$ quarter } & 309 & 2.91 & 1.00 & & & & & \\
\hline \multicolumn{11}{|c|}{ Day } \\
\hline \multicolumn{3}{|c|}{ Monday - Wednesday } & 1174 & 3.58 & 1.00 & & & & & \\
\hline \multicolumn{3}{|c|}{ Weekend } & 454 & 4.41 & 1.24 & $\begin{array}{c}0.72- \\
2.13\end{array}$ & 0.435 & & & \\
\hline \multicolumn{11}{|c|}{ Time } \\
\hline Midnight & - & 06 a.m. & 87 & 12.64 & 5.20 & $\begin{array}{l}2.30- \\
11.74\end{array}$ & 0.000 & 3.88 & $1.61-9.34$ & 0.002 \\
\hline 06 a.m. & - & Noon & 490 & 3.06 & 1.13 & $\begin{array}{c}0.54- \\
2.34\end{array}$ & 0.733 & 1.18 & $0.55-2.50$ & 0.664 \\
\hline Noon & - & 06 p.m. & 554 & 2.71 & 1.00 & & & 1.00 & & \\
\hline 06 p.m. & & Midnight & 497 & 4.23 & 1.58 & $\begin{array}{c}0.80- \\
3.11\end{array}$ & 0.180 & 1.33 & $0.65-2.69$ & 0.427 \\
\hline \multicolumn{11}{|c|}{ Type of collision } \\
\hline \multicolumn{3}{|c|}{ Single-vehicle } & 45 & 13.33 & 10.71 & $\begin{array}{l}3.90- \\
29.37\end{array}$ & 0.000 & 7.73 & $\begin{array}{l}2.70- \\
22.07\end{array}$ & 0.000 \\
\hline \multicolumn{3}{|c|}{ Truck } & 137 & 17.52 & 14.79 & $\begin{array}{l}7.43- \\
29.41\end{array}$ & 0.000 & 12.42 & $\begin{array}{l}6.16- \\
25.04\end{array}$ & 0.000 \\
\hline \multicolumn{3}{|c|}{ Car } & 989 & 1.42 & 1.00 & & & 1.00 & & \\
\hline \multicolumn{3}{|c|}{ Two-Wheelers } & 206 & 2.43 & 1.73 & $\begin{array}{c}0.61- \\
4.86\end{array}$ & 0.297 & 1.39 & $0.48-4.00$ & 0.540 \\
\hline \multicolumn{3}{|c|}{ Pedestrian } & 101 & 8.91 & 6.81 & $\begin{array}{l}2.87- \\
16.16\end{array}$ & 0.000 & 6.46 & $\begin{array}{l}2.70- \\
15.47\end{array}$ & 0.000 \\
\hline \multicolumn{3}{|c|}{ Other } & 150 & 2.67 & 1.90 & $\begin{array}{c}0.61- \\
5.87\end{array}$ & 0.260 & 2.14 & $0.69-6.64$ & 0.187 \\
\hline
\end{tabular}

\footnotetext{
a frequency

${ }^{\mathrm{b}}$ Unadjusted Odds Ratio

c Adjusted Odds Ratio

Hosmer-Lemeshow test: $\mathrm{p}=0.819$
} 


\section{Discussion}

This paper aimed to study the epidemiological profile of RTAs involving motorized two-wheelers in urban areas. Our findings show that from 2016 to 2017, the severity of RTAs was statistically higher in Parakou than in Cotonou. The severity of RTAs remains alarming in Cotonou but is still very high in Parakou. This is paradoxical because there is a higher density of motorized two-wheelers in Cotonou compared to Parakou. This is probably because of the behavior of motorcyclists or to the road environment in Parakou which seems to be more at risk. The lower risk of dying because of an RTA observed in Cotonou could also be explained by the fact that traffic corridors for motorcyclists have been established on Cotonou's main roads since 2014. The objective of this intervention was to prevent RTAs involving motorcyclists and their associated consequences by limiting their contact with other road users.

Our results suggested that RTAs were more fatal in the second quarter (but not significantly). However, according to Ngo et al. [10], the road traffic fatality rate peaked in June and December/January, which is the period of Vietnamese New Year festivities.

According to our results, RTAs between midnight and 6 a.m. were more lethal than those recorded between noon and 6 p.m. Driving under the influence of psychoactive substances, particularly alcohol and inadequate pre-hospital and hospital care during this period may explain this result. According to Kandolo et al. [11], RTAs are frequent between 6 a.m. and 12 p.m. in Lubumbashi (the Democratic Republic of the Congo). According to the authors, this situation could be justified by the period of high traffic which ranges from 6 a.m. to noon when the traffic fluctuates the most [11]. Many studies have highlighted the dangerousness of speed during this period. Speeding behavior is based on two fundamental resorts: one is to choose and maintain your basic speed whatever traffic conditions; the other relates to the tendency to compete with other users, expressing themselves mainly through rivalries when overtaking [12]. The findings of a study showed a reduction in the severity of RTAs after mandatory motorcycle helmet law [13]. According to this study, RTAs were more recorded between 8 a.m. and 11 a.m. [13]. In Ouagadougou (Burkina-Faso), the frequency of RTAs occurring in this period is because of the density of traffic as well as travel practices favoring the main roads bypassed, even in case of congestion during peak hours [14].

In this study, single-vehicle collisions, collisions between motorized two-wheelers and trucks, and collisions between motorized two-wheelers and pedestrians were $7.73,12.42$, and 6.46 times more lethal, respectively, than collisions between motorized two-wheelers and cars. Collisions involving trucks were, therefore, those with the highest risk of death for those involved. The study carried out by Madougou et al. [7] reveals that collisions between motorized two-wheelers and trucks were more deadly, which corroborates our results. The violence caused by this collision could explain this. This could also be explained by the speed at which the two vehicles were traveling at the time of the collision. According to Ngaboyirhu et al. [15], collisions between pedestrians and motorcyclists were more deadly than other collisions.

According to Ndjoukya et al. [16], the poor state of the roads in Yaoundé (Cameroon) is one cause of RTAs. Indeed, motorbike drivers dodge the "potholes" and circulate only in a tiny portion of the road, which easily generates collisions between them and other road users. Some studies have shown that crashes between motorized two-wheelers were more deadly [17-20]. The fact that motorcyclists were under the influence of alcohol and were not wearing helmets or any protective gear could explain this.

The main limitation of this study lies because the data source used does not provide information on socio-demographic characteristics such as sex, age, occupation, level of education, and many other factors that can influence the severity of RTAs.

\section{Conclusions}

At the end of this work, the type of collision, location, and time of the crash were strong and significant predictors of fatal RTAs. Many actions such as implementing an integrated model of communication strategies should target users of two-wheeled motor vehicles who do not respect traffic rules, and who adopt behavior that exposes them to RTAs. In this perspective, national and international institutions working on road safety should integrate their actions to act effectively on factors associated with fatal RTAs.

\section{Conflicts of Interest}

The authors declare no conflict of interest.

\section{Funding}

Any organization did not fund the study.

\section{Acknowledgments}

We would like to thank the National Centre for Road Safety for permitting us to use their database. 


\section{REFERENCES}

[1] World Health Organization. Global status report on road safety 2016, WHO, Geneva, 2018.

[2] G. Jacobs, A.A. Thomas, A. Astrop. Estimating Global Road Fatalities, Crowthorne: Transport Research Laboratory, TRL Report 445, 2000.

[3] M. Peden, R. Scurfield, D. Sleet, D. Mohan, A.A. Hyder, E. Jarawan, C. D. Mathers . World report on road traffic injury prevention, WHO, Geneva, 2004.

[4] M. Dabladji. Vers un système de sécurité semi-actif pour les véhicules à deux-roues motorisés, Université Paris-Saclay, Université d'Evry Val d'Essonne, Laboratoire Informatique, Biologie Intégrative et Systèmes Complexes, 2015.

[5] S. Chacus, M. Whannou. Causes et facteurs de risque des accidents des engins a deux-roues au Benin: point de vue des eleves du complexe scolaire John Wesley de Godomey-Togoudo, J Rech Sci Univ Lomé, Vol.17, No.3, 107-122, 2015.

[6] W. Haddon. A logical framework for categorizing highway safety phenomena and activity, J Trauma, Vol.12, No.3,193-207, 1972.

[7] S. Madougou, P. Chigblo, A. Tchomtchoua, E. Lawson, L. Yetognon. Incidence et impacts des accidents de la voie publique chez les conducteurs de taxi-moto en milieu tropical, Revue de Chirurgie, Orthopédique et Traumatologique, Vol.102, No.2, 201-4, 2016.

[8] A. Kpozèhouen, M. Paraïso, Y. Glele Ahanhanzo, C. Azandjèmè, V. Agueh. Issue des accidents de la voie publique : analyse à partir de données hospitalières, Bénin, Revue d’Épidémiologie et de Santé Publique, Vol.64, S215 $-6,2016$.

[9] Institut National de la Statistique et de l'Analyse Économique. Effectifs de la population des villages et quartiers de ville du Bénin (RGPH-4, 2013), Cotonou, 2016.

[10] A.D. Ngo, C. Rao, N. Phuong Hoa, D.G. Hoy, K. Thi Quynh Trang, P.S. Hill. Road traffic related mortality in Vietnam: Evidence for policy from a national sample mortality surveillance system, BMC Public Health, Vol.12, No.1, 561, 2012.

[11] S.I. Kandolo, C.M. Matungulu, P.K. Mukanya, I.K. Umba, J.N. Kabamba, O.L. Numbi, B. Kabyla Ilunga, F.M. Kaj, C.B. Lubaba, G.M. Ngongo. Facteurs associés aux accidents de la route dans la ville de Lubumbashi, Sante Publique, Vol.26, No.6, 889-95, 2014.

[12] P. Gayrard. Accidents de la route: des handicaps et des décès évitables, adsp, No.41, 2002.

[13] N.T. Ha, D. Ederer, V.A.H. Vo, A.V. Pham, A. Mounts, L.D. Nolen, D. Sugerman. Changes in motorcycle-related injuries and deaths after mandatory motorcycle helmet law in a district of Vietnam, Traffic Inj Prev, Vol.19, No.1, 75-80, 2018.

[14] A. Nikiema, E. Bonnet, S. Sidbega, V. Ridde. Les accidents de la route à Ouagadougou, un révélateur de la gestion urbaine, Lien social et Politiques, No.78, 89-111, 2017.

[15] P.M. Ngaboyirhu. Profil épidémiologique des accidents du trafic routier à Bukavu en RDC, Thesis of Medicine, Université catholique de Bukavu, 2010.

[16] G.R. Djiepmo Ndjoukya. Les défis de la sécurité routière en milieux urbain au Cameroun: le cas des motos taxis a Yaoundé, Thesis in Economics, Université de Yaoundé, 2008.

[17] G. Slesak , S. Inthalath, A. Wilder-Smith, H. Barennes Road traffic injuries in northern Laos: trends and risk factors of an underreported public health problem, Trop Med Int Health, Vol.20, No.11, 1578-87, 2015.

[18] B. Liu, R. Ivers, R. Norton, S. Blows, S.K. Lo. Helmets for preventing injury in motorcycle riders, Cochrane Database Syst Rev, No.2, CD004333, 2004.

[19] K.G. Hooten, G.J.A. Murad. Helmeted vs nonhelmeted: a retrospective review of outcomes from 2-wheeled vehicle accidents at a level 1 trauma center, Clin Neurosurg, Vol.59, 126-30, 2012.

[20] M.R. Bambach, R.J. Mitchell, R.H. Grzebieta, J. Olivier. The effectiveness of helmets in bicycle collisions with motor vehicles: a case-control study, Accid Anal Prev, Vol.53, 78-88, 2013. 